\title{
Molecular Methods for Assessment of Antibiotic Resistance in Agricultural Ecosystems: Prospects and Challenges
}

\author{
Elizabeth Luby, A. Mark Ibekwe, Julie Zilles, and Amy Pruden*
}

\begin{abstract}
Agricultural ecosystems are of special interest for monitoring the potential for antibiotic resistance to spread through the environment and contribute to human exposure. Molecular methods, which target DNA, RNA, and other molecular components of bacterial cells, present certain advantages for characterizing and quantifying markers of antibiotic resistance and their horizontal gene transfer. These include rapid, unambiguous detection of targets; consistent results; and avoidance of culture bias. However, molecular methods are also subject to limitations that are not always clearly addressed or taken into consideration in the interpretation of scientific data. In particular, DNA-based methods do not directly assess viability or presence within an intact bacterial host, but such information may be inferred based on appropriate experimental design or in concert with complementary methods. The purpose of this review is to provide an overview of existing molecular methods for tracking antibiotic resistance in agricultural ecosystems, to define their strengths and weaknesses, and to recommend a path forward for future applications of molecular methods and standardized reporting in the literature. This will guide research along the farm-to-fork continuum and support comparability of the growing number of studies in the literature in a manner that informs management decisions and policy development.
\end{abstract}

\section{Core Ideas}

- Molecular tools target DNA, RNA, or proteins as markers of antibiotic resistance.

- Molecular tools test for antibiotic resistance potential, not its expression or host.

- Molecular methods and gene targets must be consistent with research questions.

- Experimental design, controls, and statistics are important in agroecosystem studies.

- Need to link molecular data from agroecosystems with human health risk end points.
G IVEN THE SIGNIFICANT use of antibiotics in the production of livestock and produce in the United States and other countries, there is keen interest in detecting and tracking antibiotic resistance in agricultural ecosystems. Accordingly, a recent executive order issued by the US White House calling for a national strategy to combat antibioticresistant bacteria identifies the agricultural industry as a major partner in this effort (The White House, 2015). A major aspect of the draft strategy is expanded environmental surveillance of antibiotic resistance, including advancing the development and application of appropriate methods and platforms that can facilitate monitoring, which is a need that is of international urgency (Berendonk et al., 2015). Molecular methods, which target DNA or more rarely RNA or proteins, present several advantages for tracking antibiotic resistance and are rapidly expanding both in terms of technological advances and popularity. Thus, the present moment is a key juncture for evaluating the state of the science and the future prospects of molecular methods as applied to agricultural ecosystems.

A general advantage of molecular methods is that they avoid culture bias. It is estimated that $99 \%$ or more of environmental bacteria are not readily cultured using standard methods (Allen et al., 2010). Molecular methods provide direct access to the total pool of DNA, RNA, and/or protein in a sample, typically through extraction of the target or microscopic visualization. Targets are also relatively unambiguous; for example, DNA or proteins can be sequenced and compared against publicly available databases, in contrast to often laborious and ill-defined phenotypic assessments of pure cultures. Nonetheless, molecular methods are not necessarily a panacea, and there is a need to more clearly define and acknowledge both their limitations and their capabilities for tracking antibiotic resistance in agricultural ecosystems. The general weakness, particularly for DNA-based methods, is that they do not directly confirm functionality of the target within a viable host cell, although such information may be indirectly assessed through combination with other methods and appropriate experimental design. Also, molecular data are

E. Luby, Agricultural and Biosystems Engineering, lowa State Univ., Ames, IA 50011; A.M. Ibekwe, USDA-ARS, US Salinity Lab., Riverside, CA 92507; J. Zilles, Dep. of Civil \& Environmental Engineering, Univ. of Illinois, Urbana, IL 61801; A. Pruden, Dep. of Civil \& Environmental Engineering, Virginia Tech, Blacksburg, VA 24060. Assigned to Associate Editor Lisa Durso.

Abbreviations: ARG, antibiotic resistance gene; FISH, fluorescence in situ hybridization; $P C R$, polymerase chain reaction; $\mathrm{QPCR}$, quantitative polymerase chain reaction. 
not compatible with current human health risk models for antimicrobial resistance (Ashbolt et al., 2013).

For the purpose of this review, the "agricultural ecosystem" is defined to include livestock, feed, manure and associated management systems, biosolids and other fertilizer sources, soil, neighboring water bodies, and fruits and vegetables grown with direct antibiotic usage. Agricultural ecosystems present several challenges and some opportunities for tracking antibiotic resistance. For example, sample matrices along the manure-environment-produce continuum are complex, and each will impart its own recovery efficiency as well as unique background interferences. At the same time, there can be advantages, including knowledge of antibiotic usage practices for comparative studies and the existence of complementary datasets, such as those from source-tracking of fecal bacteria.

The goal of this review is to provide an overview of the advantages and disadvantages of existing molecular methods and to recommend a path forward for their application to agricultural ecosystems. In particular, we focus on (i) appropriately framing research questions based on selected molecular targets; (ii) reviewing commonly used molecular techniques, as well as newer methods on the horizon, and what questions they can help answer; and (iii) recommending parameters for standard reporting in the literature to ensure comparability across studies. As exemplar molecular methods, we describe polymerase chain reaction (PCR)-based assays, horizontal gene transfer assays, genomic and metagenomics methods, and assays that link genotype and phenotype. Finally, we provide recommendations for future research, especially in terms of experimental design and combination with other types of measurements, to achieve an integrated understanding of antibiotic resistance in agricultural ecosystems.

\section{Molecular Aspects of Antibiotic Resistance}

Antibiotic resistance is defined as a phenotypic property: the ability of a bacterial cell to survive and grow in the presence of an antibiotic concentration that is inhibitory to susceptible cells.
There are many means by which cells can achieve this, including forming biofilms to offer physical protection from the assault (Stewart and Costerton, 2001). Here we focus specifically on molecular aspects of the cell's machinery that impart resistance (Fig. 1), especially those that are genetic and therefore heritable and potentially subject to horizontal gene transfer (i.e., sharing of genes among bacteria). Defining these aspects also defines the questions that a particular assay is capable of addressing with respect to antibiotic resistance.

\section{Antibiotic Resistance Genes}

Antibiotic resistance genes (ARGs) encode the ability for bacterial cells to grow in the presence of antibiotics. They accomplish this by encoding various functions, such as pumping the antibiotic out of the cell (efflux), degrading the antibiotic, or modifying the target (e.g., chemical modification to create a cell wall that is no longer susceptible). Antibiotic resistance genes are heritable and are also commonly capable of being shared among bacteria as detailed below, so directly monitoring them can provide information about the cumulative proliferation of antibiotic resistance in a system. Subsequent to extraction of DNA from the sample of interest, ARGs are typically identified by PCRbased methods, or more recently, genomic or metagenomic techniques, as described in later sections. However, detection of an ARG indicates potential resistance because (i) the gene may not actually be expressed, (ii) the gene may have mutated to a nonfunctional form, (iii) the gene may be present in a dead cell or as extracellular DNA, or (iv) the gene may be incomplete because most methods detect portions of the ARG and not the entire reading frame

\section{Markers of Horizontal Gene Transfer}

The ability of ARGs to be shared among bacteria is likely the greatest challenge to combating antibiotic resistance (Allen et al., 2010). For this reason, several studies have incorporated tracking of markers associated with mobile genetic elements, such as plasmids, integrons, and transposons, along with ARGs in manure and soil (e.g., Nandi et al., 2004; Agerso et al., 2006; Malik et

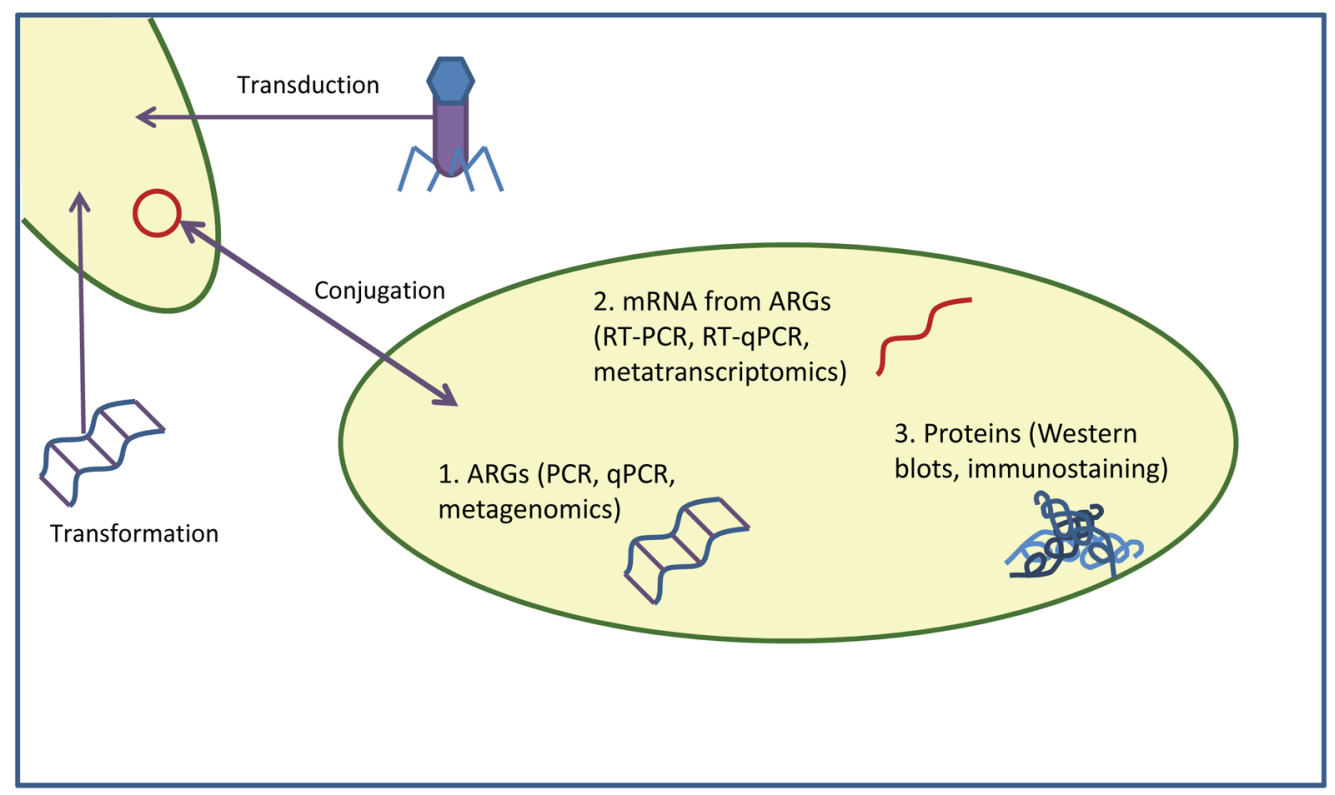

Fig. 1. Overview of molecular aspects of antibiotic resistance and methods for probing them. ARGs, antibiotic resistance genes; PCR, polymerase chain reaction; $q P C R$, quantitative polymerase chain reaction; RT-PCR, reverse transcriptase polymerase chain reaction; RT-qPCR, reverse transcriptase quantitative polymerase chain reaction. 
al., 2008; Binh et al., 2008; Musovic et al., 2014; Popowska et al., 2011; Klümper et al., 2015; Forsberg et al., 2012; Perry and Wright, 2013). However, given emerging evidence that ARG distributions in the environment appear to closely follow phylogeny (i.e., bacterial community structure) (Durso et al., 2012; Forsberg et al., 2014; Nesme and Simonet, 2015), it may be that transfer from the environment to the clinic is a rare but important event. As is the case with ARGs, methods that detect the presence of horizontal gene transfer markers (e.g., plasmids, transposons, and integrons) characterize only the potential for horizontal gene transfer. However, as we describe in this review, assays also exist for directly assaying horizontal gene transfer, which can serve to demonstrate the transfer potential and functionality of the ARG in question and to assess the rates of gene transfer to a specified bacterial recipient strain.

\section{Expression of RNA}

Monitoring RNA instead of DNA is one means by which to demonstrate that an ARG is present within a viable and active bacterium. This is typically accomplished by directly extracting RNA from a sample, instead of, or in tandem with, DNA extraction. RNA can then be subjected to reverse transcription followed by the same downstream analyses typically applied for ARGs and horizontal gene transfer markers. The major challenge with RNA analysis is that it is a highly unstable target. Owing to the ubiquity of RNases, RNA can degrade rapidly during extraction and subsequent manipulation. Therefore, it is difficult to obtain RNA of sufficient quantity and quality for further analysis, especially when extracting from complex matrices of agricultural origin, and extremely challenging to verify extraction efficiency for quantitative purposes. Other means of assessing RNA expression include reporter genes, such as the green fluorescence protein, which confirm that a gene is being induced in an in vivo system (Binh et al., 2008; Musovic et al., 2010). However, actual correspondence between RNA expression and protein production can sometimes be very low (Maier et al., 2009).

\section{Proteins}

Proteins are the molecular markers that most closely reflect cell function. Methods such as Western blots and immunostaining can be applied to detect specific proteins related to antibiotic resistance. For example, carbapenemase presence and activity was confirmed in Acinetobacter baumannii to understand conditions that control actual expression of resistance (Liao et al., 2014). However, these methods are usually highly specific for a given protein, which limits their applicability for measuring antibiotic resistance in environmental samples where a variety of homologous proteins might interfere with analysis. Matrix complexities are particularly problematic for protein analyses. To our knowledge, these approaches have not been applied in environmental samples from agroecosystems, and they are not considered further in this review.

\section{Molecular Methods for Assessing Antibiotic Resistance}

In the following sections, methods for detecting, characterizing, and/or quantifying molecular targets pertaining to resistance are discussed. For most methods, this requires a priori selection of a target, which should ideally be done bearing in mind the likely host bacteria. For example, tetracycline ARGs have been relatively well characterized, and most tend to be carried by either Gram-positive or Gram-negative bacteria (Roberts, 2012). Similarly, targets corresponding to resistance to the antibiotics of interest (which also generally treat Gram-positive or Gramnegative infections) is also an important consideration. With the aim of capturing ARGs corresponding to a range of antibiotic classes and with emphasis on clinical concern and importance to horizontal gene transfer, the European COST (Cooperation in Science and Technology) Action DARE (Detecting Evolutionary Hotspots of Antibiotic Resistance in Europe, TD 0803), recently suggested the following targets for monitoring: the class 1 integron, int 1 ; sulfonamide ARGs, sul 1 and sul2; $\beta$-lactam ARGs, blaCTX-M and blaTEM; a quinolone ARGs, $q n r \mathrm{~S}$ and 6-ib-Cr; macrolide ARGs, ermB and ermF; the ARG cassette marker, aac; a glycopeptide ARG, vanA; and a methicillin ARG, mecA (Berendonk et al., 2015). Bearing in mind multiple considerations in choosing targets, the following sections focus on (i) defining the methods and what they achieve, with particular attention to quality control issues and recommendations for reporting in the literature; (ii) illustrating the role of experimental design through identification of pertinent studies; and (iii) presenting a prospectus for future application of molecular tools for the study of antibiotic resistance in agroecosystems.

\section{Polymerase Chain Reaction-Based Assays \\ Traditional Polymerase Chain Reaction}

Polymerase chain reaction has become a popular method for detecting ARGs of interest in environmental samples because it is highly sensitive, provides relatively rapid results $(2-3 \mathrm{~h})$, and yields direct information about the DNA sequence of interest. It is an enzyme-based assay using oligonucleotide primers that are complementary to the flanking regions of the target to amplify target genes or gene fragments. Polymerase chain reaction has been successfully and widely applied to detect ARGs in samples from agroecosystems since at least 2001 (Chee-Sanford et al., 2001). A wide range of primers that target specific ARGs are widely available in the literature.

There are, however, challenges and limitations to the application of PCR to agricultural ecosystems (Goyer and Dandie, 2012). In particular, PCR is dependent on DNA extraction, which will vary in efficiency across matrices and is likely to carry through inhibitors that can interfere with PCR. These limitations can lead to false negatives. On the other hand, PCR can be prone to nonspecific reactions (i.e., amplifying the wrong target), resulting in false positives. As noted previously, PCR by itself does not provide information about whether the target ARG was actually being expressed in the environment. Inactive ARGs could, however, still be of importance, given that extracellular DNA can sometimes be taken up and expressed by other bacteria, although the extent and frequency that this occurs in natural environments is still uncertain and a subject of great interest (Chen and Dubnau, 2004; Seitz and Blokesch, 2013). Finally, the traditional form of PCR is not quantitative. The most direct information that PCR can provide about ARGs is that they are either present or below detection. 
When reporting PCR data for samples from agricultural ecosystems, in addition to verifying expected product size by gel electrophoresis, it is strongly advisable to sequence the PCR products from a representative subset of samples to ensure that the PCR is amplifying the intended target. In addition to verifying the specificity of the target, sequence variability among ARG variants may also be of interest and can be explored by comparing with GenBank or other databases (Koike et al., 2007; Garder et al., 2014). It is also important to be consistent in applying quality control measures, such as including blank samples and reporting the criteria for scoring samples as positive or negative. Ideally, internal amplification controls can also be included to avoid false negatives resulting from enzyme inhibition (Hoorfar et al., 2004). Diluting extracted DNA is often an effective means of diluting out inhibitors, and a dilution series can be performed to identify the dilution that yields the optimal signal for each sample. Otherwise, spiked matrix controls are sometimes applied to verify a true negative (Pei et al., 2006), but they are laborious. There is some question whether PCR inhibition varies as a function of template concentration (Wilson, 1997), suggesting that low spiking concentrations are best. Before the PCR, selection of the appropriate DNA extraction procedures to optimize yield and purity is critical, particularly for complex samples, and the same method should be implemented throughout a project to ensure comparability of results. Bead-beating appears to be a particularly important step in obtaining high-quality DNA from environmental samples (Guo and Zhang, 2013). Finally, it is important to report the specific PCR primers used, noting corresponding citations and validation or presenting validation results, and the essential assay conditions, such as reaction chemistry and annealing temperature.

\section{Real-Time Quantitative Polymerase Chain Reaction}

Quantitative PCR (qPCR) provides the benefits of PCR and also yields quantitative information about the abundance of the target ARG. For qPCR, the reaction itself is modified to include either probes, which fluoresce when bound to the target DNA, or dyes, such as SybrGreen, that bind to double-stranded DNA. A specialized instrument then detects the amplification of the target DNA during the PCR reaction. The threshold cycle, or CT value, where the signal crosses the baseline can be compared against a standard curve to determine the gene copy number of an ARG. Quantitative PCR has also recently been adapted to manage longer templates (up to $6 \mathrm{~kb}$ ), which is essential to capture damage events and thus must be applied if the intention is to assess the effects of different treatments on the DNA itself (Suess et al., 2009; McKinney and Pruden, 2012; Rodríguez et al., 2013). A major drawback of PCR and qPCR is that only a limited number of genes can be targeted in a given study. One recent large-scale study applied PCR and qPCR to track 46 gene targets associated with plasmid incompatibility groups, integrons, and ARGs in fields subject to manure application (Marti et al., 2013), but this comes at significant cost and labor. The resulting need to select specific ARGs or other genetic elements to monitor a priori may bias the results.

In agroecosystems, qPCR has been widely applied over the last decade to track both ARGs and markers of mobile genetic elements; a few illustrative examples are cited here. One early study quantified genes encoding sulfonamide and streptomycin resistance and markers of horizontal gene transfer (integrases) in chicken litter (Nandi et al., 2004). Another early study quantified tetracycline resistance genes in cattle feedlot lagoons (Smith et al., 2004). Quantitative PCR has been successfully applied to diverse agroecosystem sample types, including swine lagoons (Koike et al., 2007), groundwater (Koike et al., 2007), river sediments (Pei et al., 2006), manure (Heuer and Smalla, 2007), and soil (Heuer and Smalla, 2007).

As with any quantitative method, it is critical to determine and report the limit of quantification, or the lowest standard on the linear portion of the standard curve that can be trusted for quantification. $R^{2}$ values for calibration curves should be reported along with the number of points and replicates on the curve. The efficiency is also commonly reported, with an ideal value of 1.0 (for clinical targets), although values tend to be as low as 0.7 for assays applied to agricultural systems. If consistent, the lower efficiency value is acceptable. Because DNA extracts are likely to contain PCR inhibitors, it is wise to perform a dilution series to identify the dilution that results in the strongest and most consistent signal. It is important to take such dilutions into consideration, as well as those occurring during DNA extraction and other sample processing steps, when determining the limit of quantification from the standpoint of the actual samples, with units reported as gene copies per milliliter or gram of matrix material (noting dry or wet weight). Normalization to $16 \mathrm{~S}$ rRNA genes is thought to aid in accounting for minor variations in extraction efficiency while also providing an indication of the proportion of total bacteria carrying ARGs (although the correspondence here is not ideal and likely varies across systems) (Pei et al., 2006; Pruden et al., 2006; Knapp et al., 2010; Heuer et al., 2011b). The matrices common in agricultural environments (e.g., manure) can be highly heterogeneous and may require multiple samples to obtain accurate results. Inclusion of blank samples with every run is also important to eliminate concerns regarding any background contamination with the target, which can elevate the limit of quantification considerably. Including blank extractions can also help make sure that DNA extraction materials and kits are target free. It is also useful to report the source of the positive control, such as genomic, environmental, or plasmid DNA, and how the quality was verified.

\section{Quantitative Polymerase Chain Reaction Array}

The recent development of $\mathrm{qPCR}$ arrays is promising for addressing the throughput limitations associated with qPCR because these arrays allow simultaneous quantification of hundreds of ARGs and other genes of interest with much improved quantitative capability relative to microarrays (Wagner et al., 2007). Qiagen recently developed the Antibiotic Resistance Genes Microbial DNA qPCR Array, which is configured for 96- or 384-well plates and includes primers for quantification of 97 ARGs and 87 virulence factors. Alternative systems, such as Wafergen Bio-systems SmartChip Real-Time PCR, allow for qPCR arrays with primers selected by the researchers. The latter approach was applied in recent studies to quantify and track the enrichment of 244 ARGs and nine transposase genes in manure and soil samples (Zhu et al., 2013; Wang et al., 2014).

One drawback of the qPCR array is the inability to optimize each individual qPCR assay. For example, the annealing temperature, which is critical for governing specificity of binding of 
primers, is uniform throughout the array. It is also not possible to recover and sequence products, as can ideally be done to confirm specificity. Detection limits are also inevitably higher, given that the reaction volume is limited to nanoliters. Additional research would be beneficial to further validate the qPCR array approach for agricultural ecosystems.

\section{Horizontal Gene Transfer Assays}

Horizontal gene transfer can be studied through detection and quantification of specific marker genes associated with mobile genetic elements (Nandi et al., 2004); direct assays of transfer via conjugation (Musovic et al., 2010; Binh et al., 2008), transduction (Coque et al., 2008), transformation (Chen and Dubnau, 2004; Dodd, 2012; Seitz and Blokesch, 2013); or retrospective genome or metagenome analyses (Nesme et al., 2014; Nesme and Simonet, 2015). Methods focusing on specific marker genes are amenable to the PCR-based approaches described above and are subject to the same limitations. Direct assays can be applied to estimate transfer rates, to determine the host range of an ARG on mobile elements, and to confirm that a putative ARG is actually functional. Their main limitation is the requirement for recipient cells to be culturable, although a reporter gene approach, such as green fluorescent protein, can reduce the need for culturing and selection steps (Musovic et al., 2010; Klümper et al., 2015).

\section{Conjugation Assays}

Bacterial conjugation refers to the exchange of conjugative transposable genetic elements or plasmids through close physical contact between a donor and recipient bacterium (Zechner et al., 2003). Marker genes used to study conjugation include the incompatibility group (Inc) subset of broad host range plasmids (Gotz et al., 1996; Schlüter et al., 2007; Musovic et al., 2010) and features of conjugative transposons, including forward and reverse integrase and excisase (Zhu et al., 2013). Roberts and Mullany (2011) have extensively reviewed the Tn916-like genetic element family known to contain ARGs. Multiple studies have confirmed the presence of tetracycline and macrolide ARGs in transposable elements using PCR and sequencing techniques (Roberts et al., 2006; Cochetti et al., 2008; Del Grosso et al., 2009). Conjugation can also be studied directly, using a recipient strain and a plasmid-containing donor strain that transfers a distinct selectable or expressible marker. This approach has the advantage of providing direct information on transfer rates and host range but shares the limitations of other culture-based methods in not reflecting the full diversity of environmental microbial communities. Also, most prior work has focused on Gram-negative bacteria, whereas conjugation in Gram-positive bacteria is less characterized (Goessweiner-Mohr et al., 2013).

Plasmids harboring ARGs can be identified through screening of culturable isolates, capturing plasmids with culturable recipients (also termed exogenous isolation) (Smalla and Sobecky, 2002), or isolating plasmid DNA directly from an environmental matrix (Couturier et al., 1988). Plasmid capture requires a known recipient strain that does not harbor the target ARGs, is not commonly found in the environment being tested, and does not contain a plasmid (Binh et al., 2008). It can be conducted in the laboratory, using environmental samples as the donors, or by incubating recipient bacteria in the environment of interest. Two previous studies used a plasmid capture approach to demonstrate exogenous transfer of plasmid-borne ARGs from Gram-negative bacteria in manure samples (Agerso and Sandvang, 2005; Binh et al., 2008). In all of these approaches, the plasmid DNA can be sequenced to identify the plasmid and any ARGs it carries. In the converse approach, donor cells containing broad host range plasmids, such as IncP and IncPromA, can be incubated with the sample of interest to identify permissive bacteria (Musovic et al., 2010). This approach was recently applied to demonstrate that manure application increases permissivity of soil bacteria to plasmid uptake (Musovic et al., 2014) and that recipient bacteria can be spread across multiple Phyla, including Gram positives (Klümper et al., 2015).

Each approach to assaying conjugation has its advantages and disadvantages. As with ARGs, identification and quantification of conjugative markers by PCR or qPCR will provide information with respect to conjugative potential but cannot confirm that conjugation is occurring within the target environment. Also, often the presence of several gene markers and ARGs is necessary to confirm the presence of a conjugative plasmid or transposon (Carattoli et al., 2005; Cochetti et al., 2007). Because a number of ARGs may be carried by the host, it may not be possible to confirm which one is the driver of phenotypic resistance. Screening of culturable isolates confirms the presence of the plasmid or conjugative transposon in a living host. However, the requirement for culturing and isolation is a challenge for accessing the vast diversity of conjugative elements present in a typical agricultural sample (Smalla and Sobecky, 2002). Exogenous isolation, on the other hand, is only restricted by the host range of the conjugative element, but will not provide information on the original host bacteria.

Because there are many factors that influence conjugative mating experiments, detailed reporting of conditions applied is required in the methodology section. Key variables include antibiotic concentrations, results of susceptibility testing to determine minimum inhibitory concentration, incubation periods, donor and recipient strain information, enumeration of strains before/after mating, negative controls to account for background, and PCR primers, conditions, and controls. In particular, it may also be necessary to vary the ratio of donor to recipient or add low levels of antibiotics to optimize the assay (Facinelli et al., 1993). Additionally, assays aiming to identify individual transposable elements responsible for transferring resistance need to report all primer combinations used to screen the isolate.

\section{Transduction Assays}

Transduction is the virally mediated exchange of DNA that is generally limited between closely related strains and has only been demonstrated for a few species. Transduction occurs when the virus transfers bacterial DNA from its previous host into a new bacterial host, which then incorporates the new genes into its genome (Frost et al., 2005). Transfer of ARGs via transduction may be a much more widespread phenomenon than previously thought (Colomer-Lluch et al., 2011b; Balcazar, 2014). Because next-generation DNA sequencing is expanding in application for sequencing bacterial genomes, prophages and prophage-like elements indicative of phage infection have been observed nearly universally among bacterial isolates (Canchaya et al., 2003; Casjens, 2003). Phages that are able to transfer 
antimicrobial resistance are diverse, ranging from specific to broad-host, and are not dependent on homologous recombination (Balcazar, 2014). Certain environmental conditions, such as ultraviolet radiation, are particularly conducive to stimulating lytic pathways (Brabban et al., 2005).

Transduction has been reported in fecal waste from cattle, pigs, and poultry and in environmental water and plant surfaces (Fineran et al., 2009). One line of evidence for the occurrence of transduction is isolation of phages and analysis of the nucleic acids that they carry by PCR or qPCR (Colomer-Lluch et al., 2011a). Quantitative PCR was used to quantify $b l a_{\text {TEM }}$ and $b l a_{\text {CTX-M }}$, which encode $\beta$-lactamases that are widespread among Gram-negative pathogens (Coque et al., 2008), and mec $A$, which encodes penicillin-binding protein $2 \mathrm{a}$, associated with methicillin resistance in staphylococci (Tsubakishita et al., 2010) in the viral DNA fraction of animal fecal material. Evidence suggests that phages have served as vectors for carrying ARGs from environmental bacteria to clinical bacteria (Schmieger and Schicklmaier, 1999; Witte, 2004).

In addition to the above-mentioned meticulous controls noted for conjugation assays, appropriate controls to rule out DNA from a nonviral origin during phage DNA extraction are important for transduction assays. Therefore, samples taken after DNase treatment, but before the phage DNA was extracted from the capsid, should be used as template for subsequent confirmation by PCR or qPCR (Colomer-Lluch et al., 2011b). Researchers should exercise caution with their control strategies, and ideally the final PCR or qPCR product can be sequenced for confirmation. Determination of the baseline for the target genes and quantification relative to that baseline is important for determining the efficiency of the assays.

\section{Transformation Assays}

Transformation is the ability of bacteria to take up and incorporate extracellular DNA, which is fundamental to the concept of ARGs as pollutants (Dodd, 2012). As with conjugation and transduction, natural transformation affects antibiotic resistance because it can result in transfer of ARGs among different types of microorganisms and thus may enhance their persistence and dissemination. Although the capability to be transformed (i.e., competence) has generally been thought to be limited, especially as a natural process, it has now been demonstrated for at least 80 strains of bacteria (Lorenz and Wackernagel, 1994; Johnston et al., 2014). In addition to the limited known range of naturally competent cells, the presumed short half-life of free DNA has also been perceived as a limitation. There is growing evidence, however, that the amount of extracellular DNA in the environment is significant and that it can persist, primarily through its adsorption to various soil fractions, such as clays and sediments, which protect it from degradation by DNase (Levy-Booth et al., 2007; Pietramellara et al., 2009). For natural transformation, nutrient availability and high cell density can be important triggers (Lorenz and Wackernagel, 1994; Johnston et al., 2014), while the range of dissemination across different types of bacteria is controlled at two stages: DNA uptake and DNA integration (Johnston et al., 2014). Some bacteria have highly specific DNA uptake systems and are therefore effectively transformed only by DNA from closely related species, whereas others appear to be indiscriminant in their uptake of DNA yet still are thought to incorporate only highly related DNA. The requirement for extracellular DNA to be integrated into the chromosome generally necessitates some degree of homology between donor and recipient cells. However, this requirement does not apply to natural transformation of plasmid DNA, where recircularization of the plasmid generally allows persistence of the introduced DNA. Transformation pili can also play an important role in the uptake of exogenous DNA (Johnston et al., 2014). Known naturally competent bacteria include Azotobacter vinelandii, Pseudomonas stutzeri, and Acinetobacter calcoaceticus, whereas the Tn 917 transposon (Lorenz and Wackernagel, 1994) and the IncP-1 incompatibility plasmid group are known to be compatible with a broad host range (Schlüter et al., 2007).

Unlike conjugation or transposition, for natural transformation there are no representative genes or sequences that can be targeted with molecular methods to assess the extent of transfer in a particular environment, nor can gene transfers identified during genome analysis be definitively attributed to natural transformation. Because of these limitations, available methods for monitoring natural transformation all involve mixing donor DNA containing a known selectable or detectable marker with competent recipient cells and then recovering and quantifying successfully transformed cells; a detailed description of methods for natural transformation assays is available (Ray and Nielsen, 2005).

The primary advantage of natural transformation assays is that they are a direct and quantitative measure of gene transfer. Among the matrices relevant to agroecosystems, to our knowledge natural transformation assays have only been conducted in soil microcosms (e.g., Nielsen et al., 1997; Demaneche et al., 2001). In these studies, both the donor DNA and the recipient cells were spiked into soil microcosms, and transformation frequencies were quantified under different conditions and timescales. A key weakness of natural transformation assays, as with any culture-based method, is our inability to recover many indigenous soil microorganisms. The relevance of transformation frequencies to a particular environment depends on how representative the recipient cells are. In theory, the approaches used for conjugation could be adapted for the study of transformation, for example, by using manure or soil samples as the source of extracellular DNA, although to our knowledge this has not been done. In the context of ARGs as pollutants, transformation assays can be used to assess whether a treatment process served to effectively inactivate ARGs (Dodd, 2012). For such purposes, model organisms that are indiscriminate in their DNA uptake (i.e., they do not show specificity for particular DNA sequences), such as Acinetobacter sp. BD413 (Ray and Nielsen, 2005) or $A$. vinelandii (Renaud et al., 1989), are ideal.

When conducting natural transformation assays, no-DNA controls are required to assess background levels of resistance, whether preexisting or arising spontaneously during the transformation assay. Extensive replication is also essential because the biological variability can be large even for pure cultures and controlled conditions (e.g., Lu et al., 2010). Important parameters to report include source and concentrations of both the DNA and the potential recipient cells used in the transformation assays as well as assay conditions (e.g., time, temperature, mixing, and solution chemistry) and the type and number of replicates. 


\section{Metagenomics Methods}

The advent of next-generation DNA sequencing methods has sparked a new era in molecular characterization of environmental ecosystems. The primary advantage of these methods is that they circumvent PCR and thus the need to select genetic targets, such as specific ARGs and mobile genetic elements, a priori. Collective genomes in a given sample (metagenomes) can be sequenced in a single step (e.g., yielding 10-1000 Gb of DNA sequences in a single HiSeq 2500 Illumina lane). Antibiotic resistance genes or other targets of interest (e.g., plasmids, transposons, and virulence factors) can then be detected and quantified by searching against online databases using publically available tools, such as MG-RAST (Meyer et al., 2008), the Integrated Microbial Genome database (IMG) (Markowitz et al., 2012), or the Comprehensive Antibiotic Resistance Database project (CARD) (McArthur et al., 2013).

Recent metagenomics studies have revealed a wide range of ARGs and mobile genetic elements from different ecosystems (Kristiansson et al., 2011; Bengtsson-Palme et al., 2014). Manure and its impacts on soil are of special interest in agricultural ecosystems. In particular, soil metagenomes have been revealed to contain a highly diverse pool of ARGs, including the most common types of resistances found in other environmental metagenomes (Donato et al., 2010; Nesme and Simonet, 2015).

Because metagenomics provides information on the total sum of genes present, examination of data sets can provide broad contextual information beyond identification of ARGs. For example, identification of horizontal gene transfer markers, such as plasmids and transposons, can provide clues about how ARGs may have spread from one environment to another (Ochman et al., 2000; Bengtsson-Palme et al., 2014; Nesme and Simonet, 2015). Metagenomics has also been applied to provide a comprehensive comparison of ARGs and markers of horizontal gene transfer in manure and agricultural soils (Durso et al., 2012; Wichmann et al., 2014; Fang et al., 2015). Comparing the suites of ARGs present in different environments or under different environmental conditions can provide insight into potential controlling factors. For example, analyses of metagenomic data suggest that the soil has a high diversity of ARGs (Durso et al., 2012; Nesme et al., 2014) and that the majority of these soil ARGs are subject to vertical, rather than horizontal, gene transfer. Metagenomics has also been key for advancing efforts to determine to what extent ARGs in the clinic originate from the environment and via which mechanisms (Forsberg et al., 2012; McGarvey et al., 2012; Gibson et al., 2015). Evidence of mutation can also be gleaned to gain insight into how ARGs may have gained or lost functionality in the system (Schmieder and Edwards, 2012). Although it requires greater effort and expertise in bioinformatics, assembly of individual genomes within metagenomes can provide valuable information regarding which ARGs are present in which hosts (Henry et al., 2011), a question that cannot be answered with PCR-based methods. However, quantitative information can be lost on assembly (Thomas et al., 2012)

As is the case with PCR, metagenomics applied directly to DNA extracted from the environment cannot confirm the functionality of a putative ARG. However, functional metagenomics can achieve this goal (Pehrsson et al., 2013; de Castro et al., 2014; Su et al., 2014; Wichmann et al., 2014). Functional metagenomics is achieved by fragmenting extracted DNA and inserting it into plasmids, such as the bacterial artificial chromosome, that are able to accommodate large inserts (Uchiyama and Miyazaki, 2009). The ligated plasmids are then transformed into hosts, such as Escherichia coli, and plated onto media selective for the antibiotic resistance trait of interest. Functional metagenomics has been applied to identify several ARGs corresponding to various antibiotic classes and has been successfully performed on various animal manure and gut microbiota (Zhou et al., 2012; Su et al., 2014). Functional metagenomics can also be applied to discover new antibiotics (MacNeil et al., 2001; Gillespie et al., 2002; Lim et al., 2005) and antibiotic resistance elements (Bengtsson-Palme et al., 2014). The main disadvantages of functional metagenomics are the labor involved and the biases in gene expression that are associated with the selection of a particular host. It has been reported that the ARGs discovered do not tend to be representative (de Castro et al., 2014).

One particular challenge of metagenomics is that available databases still are not well populated or curated, focusing mainly on clinical ARGs, which affects the integrity of comparisons of ARG profiles across samples, especially environmental samples. If similar genes are not present in the database, searches may miss unknown bioactive molecules. Thus, genomic sequencing of well-characterized pure cultures and functional metagenomics libraries, along with annotation of genomes and rigorous maintenance of the databases, will be critical for the future of metagenomics-based approaches. With intense deep sequencing of environmental samples and relevant knowledge in bioinformatics, better databases can inform the assembly of genomes from metagenomic data sets and help identify novel ARGs (McArthur et al., 2013). Improved pipelines can further aid in the efficiency and accuracy of ARG identification (e.g., Yang et al., 2014). Correspondingly, advanced analysis of metagenomics data sets, such as assembly of genomes, requires a high level of expertise. Standardized and publically available pipelines for achieving advanced bioinformatics analysis would be of farreaching value. At the present time, arguably the largest barrier to expanded application of metagenomics methods for assessing antibiotic resistance in agricultural ecosystems is cost. Currently, one MiSeq Illumina lane typically costs about $\$ 3500$ and ideally should be applied to one sample at a time to ensure sufficient depth to capture all ARGs and other sequences of interest. Thus, currently metagenomics is best applied to a representative subset of samples and is used to guide selection of markers for broader analysis across samples, such as via qPCR. Emerging, low-cost DNA sequencing technologies, such as PacBio (Pacific Biosequences), may enable metagenomics to surpass PCR-based approach.

In reporting metagenomics data, it is critical to indicate what kinds of extraction and amplification methods were used and what measures were taken to avoid contamination of exogenous DNA sources. Given that data analysis approaches are still evolving, it is especially important to describe the methods used in detail, including assumptions and simplifications made to the data sets. Because the current cost of metagenomics is still prohibitive for most researchers, statistical replication is not always possible. Thus, study design is especially critical to highlight key contrasts, and complementary analyses, such as qPCR, should be used to verify general conclusions. 


\section{Assays That Link Genotype and Phenotype}

Although the vast majority of molecular methods detect or quantify ARGs, the possible disconnect between genetic potential and phenotypic reality calls for complementary methods that provide better links between the two layers of information. Culture-based assays, followed by genotyping, can serve this purpose but are plagued by slow response time and limitation to the narrow fraction represented by cultivable bacteria. Some efforts seek to expand the capabilities of molecular techniques to integrate information about antibiotic resistance phenotype into single, rapid assays. For macrolide-lincosamide-streptogramin type $B$ resistance, which arises from a specific ribosomal methylation, detection has been accomplished by membrane hybridization (Jindal et al., 2006; Angenent et al., 2008) and fluorescence in situ hybridization (FISH) methods (Trebesius et al., 2000; Zhou et al., 2009). However, this approach is specific to macrolide-lincosamide-streptogramin type B resistance. Extension to other antibiotic resistance mechanisms is theoretically possible (e.g., via antibodies to a protein involved in resistance) but would still be mechanism specific. More recently, molecular techniques, specifically a species-specific padlock probe, have been used to quantify growth after only two or three generations (Mezger et al., 2015). By conducting these assays with and without antibiotics, this approach was used to rapidly assess antibiotic resistance.

Both of these molecular phenotypic methods are quantitative. As compared with genotypic methods, they have the advantage of directly assessing the resistance phenotype, and, compared with culture-based methods, they are considerably faster (i.e., a few hours vs. $\geq 24 \mathrm{~h}$ ). Membrane hybridizations and FISH have both been applied in manure and soil samples (Jindal et al., 2006; Zhou et al., 2009). Although membrane hybridizations scale up more easily, the FISH method has the advantage of being able to identify the resistant microorganisms when used in combination with phylogenetic probes (Zhou et al., 2009). The padlock probe (i.e., long oligonucleotides with ends complementary to adjacent target sequences) detection is currently in development for clinical use. Although in theory the same approach can be applied to environmental samples, there are likely to be difficulties in these more complex matrices. To date, it has also only been used for detection of specific target organisms. It should be possible to use probes of varying specificity to measure resistance in groups of varying taxonomic levels. However, for broader groups and environmental microorganisms, choosing appropriate growth conditions will become a major concern.

\section{Role of Experimental Design}

Regardless of the molecular method selected to assess antibiotic resistance, the experimental design is essential and must be carefully crafted to address specific research questions. The origins of resistance are complex, and agroecosystems are especially complex and diverse environments. In particular, the sections below focus on the following aspects of experimental design: (i) incorporating appropriate controls and accounting for background antibiotic resistance, (ii) obtaining representative samples and statistical resolution in spatially heterogeneous and temporally variable systems, (iii) applying study designs that provide insight into factors at play in the field, (iv) obtaining insight into ARG hosts and their viability, and (v) combining methods strategically. For molecular methods in particular, it is also important to consider whether the targets being detected are likely to be active and what microorganism(s) they might reside in. For example, it is important to consider which antibiotics are being used, what kind of bacteria they target, and whether Gram-positive or Gram-negative bacteria are of interest. A few exemplary studies are highlighted here to illustrate some of the ways these challenges are being met.

\section{Background and Controls}

Because ARGs are naturally occurring, accounting for background sources of antibiotic resistance is critical (Rothrock et al., 2016). There are three common approaches to address background resistance: historical comparisons, pristine environments as controls, and antibiotic-free or organic agricultural systems as controls. Historical comparisons provide important insight into the prevalence of background resistance and the influence of human activity. For example, examination of arctic soil cores (Allen et al., 2009; Lang et al., 2010) and soil archives (Knapp et al., 2010) preserved before the antibiotic era provide insight into how anthropogenic activities have shaped the trajectory of evolution of ARGs and mobile genetic elements.

To specifically address the effects of agricultural practices, Pruden and colleagues compared pristine upstream regions of the Cache-La-Poudre River located in the Rocky Mountains to downstream urban and agriculturally affected zones of the watershed (Pruden et al., 2006; Storteboom et al., 2010). Using qPCR, it was possible to demonstrate that ARGs were elevated downstream. A follow-up study using geo-spatial analysis further revealed a significant correlation between the numbers of sul 1 ARGs in river samples and the capacities (i.e., number of animals) in upstream livestock facilities (Pruden et al., 2012). For soil studies, a common approach is to choose a "pristine" soil that has not previously been subject to manure or biosolids application or irrigation with reclaimed water (Wang et al., 2014). However, this approach neglects any effects that nutrient addition alone may have on antibiotic resistance; a recent study suggests this nutrient effect could be an important consideration (Udikovic-Kolic et al., 2014).

An alternative approach is to compare conventional animal production and waste management systems with antibiotic-free or organic systems. This approach has also provided strong evidence for an increased prevalence in antibiotic resistance associated with agricultural antibiotic use (e.g., Jindal et al., 2006; Peak et al., 2007; Zhou et al., 2009; McKinney et al., 2010). Limitations associated with this approach include variations across agricultural practices that can make it difficult to isolate the specific variable of antibiotic use, evidence that antibiotics (Zhou et al., 2009) and antibiotic-resistant bacteria may be present in the absence of use (Thames et al., 2012), and therapeutic antibiotic use for ill animals on organic farms (McKinney et al., 2010).

\section{Obtaining Representative Samples and Statistical Resolution}

As with any research, an appropriate sampling plan is necessary to ensure that samples are representative and statistical power is sufficient to test the hypotheses. This can be 
particularly challenging for large-scale agricultural studies with complex matrices. For heterogeneous environments, such as compost, lagoons, and soils, it is often practical to sample several locations within each replicate and combine these samples before analysis. For PCR-based methods, which are relatively high throughput, it is usually feasible to include sufficient experimental replication. Care may be needed to select appropriate statistics, however, given that qPCR data often span several logs. Log transformations coupled with nonparametric statistical tests, such as the Wilcoxon ranked sum test, can be implemented to analyze non-normal data sets. In the case of metagenomics, costs are still generally too prohibitive to use appropriate experimental replication, and thus it is important to avoid extrapolating too much from individual samples (Prosser, 2010; Lennon, 2011). However, metagenomics is ideal for identifying candidate ARGs and selecting markers for qPCR, which will provide higher sensitivity and can be applied economically across a wider range of samples for quantitative comparisons.

\section{Simplifying Complexity Encountered in the Field}

A recent study exemplifies the complexity associated with applying molecular methods in the field. Marti et al. (2013) compared produce grown with raw dairy or swine manure versus equivalent application of chemical fertilizer as the control. The study was well controlled; the plot was not manured or irrigated in the $3 \mathrm{yr}$ before the study, and no other manure or livestock applications were within a $2-\mathrm{km}$ radius. However, various challenges were encountered, including weeds, pests, and atypical rain/temperature patterns, and responses to these challenges (e.g., application of herbicide, pesticide, and early harvest) added complexity to the interpretation of the results. Ultimately, although soil receiving manure was enriched in antibiotic-resistant bacteria and ARGs, it was difficult to assess if there were effects on the produce. Although field experiments are an essential research component, alone they are not likely to provide firm conclusions about the parameters controlling dissemination of antibiotic resistance in the environment.

Approaches that simulate the agroecosystems under controlled conditions can be complementary to field studies. For example, Looft et al. (2012) were particularly rigorous in their study on the effect of antibiotics on the intestinal microbiome of swine. The researchers reared the pigs under hygienic conditions and administered the antibiotics themselves, maintaining an isolated, unmedicated control group from the same litter. Microcosm and mesocosm studies are common and have allowed focused investigation of specific parameters, such as aerobic and anaerobic manure treatment and temperature (Pei et al., 2007). An elegant study by Engemann et al. (2008) used mesocosms equipped with biofilm traps to simulate lagoons receiving cattle feedlot runoff with and without oxytetracycline addition, river water supplementation, and light exposure. Microcosm and field sampling have also been used in combination, for example to investigate antibiotic resistance in manure-amended soils (Zhou et al., 2010; Heuer et al., 2011b). The ultimate goal of such studies is to identify key parameters affecting the prevalence of antibiotic resistance and the fate of ARGs to inform future fate models.

\section{Relating Molecular Data to Viability and Activity of Host Bacteria}

A common limitation of molecular methods is the inability to confirm whether or not the molecular target being detected is active. The most rigorous approach to address this issue is to isolate the cultures of interest before molecular analysis. Although effective, this approach is severely limited by our inability to culture many environmental microorganisms. For example, Sato et al. (2014) isolated $E$. coli resistant to ceftiofur (a third-generation cephalosporin) from dairy cows with and without ceftiofur treatment. Positive isolates were then subjected to disc diffusion assay to assess phenotypic resistance to several antibiotics and PCR to identify specific ARGs that they carried. Although there was not a statistically significant increase in $E$. coli resistant to ceftiofur from ceftiofur treatment, subsequent characterization of the isolates suggested an increase in resistance to several $\beta$-lactam antibiotics and in horizontal gene transfer of the $\beta$-lactam ARGs on self-transmissible plasmids. Studies such as these illustrate the intricate experimental detail and effort that can be required to confirm the presence of an ARG in a live bacterium and its ability to be expressed and horizontally transferred. However, a trade-off with such a high level of experimental effort is that it is difficult to obtain sufficient statistical power. Also, culturing specific organisms will not characterize potential effects on the microbial community as a whole and will not account for responses of bacteria that are viable but nonculturable, which is a common response of bacteria to stress such as starvation and antimicrobials (Li et al., 2014).

Methods that quantify DNA do not directly distinguish between live or dead cells or between intracellular and extracellular DNA. In some cases, with appropriate study design, DNA can be an indicator of response of living bacteria in a system. For example, if a target gene is increasing in a closed system with time, growth of the host is the logical explanation. Other methods are designed to selectively quantify DNA that is present within a viable cell by pretreating samples with selective dyes, such as propidium monoazide and ethidium monoazide, that penetrate compromised cell membranes and render the DNA unsuitable for PCR (Rudi et al., 2005; Nocker et al., 2006; Luo and Angelidaki, 2014). Extraction methods that distinguish intracellular DNA from extracellular DNA have also been reported and applied to manure lagoons (Zhang et al., 2013). Approaches to distinguish between live or dead cells and intracellular and extracellular DNA have not been widely applied in agroecosystems.

\section{Strategic Combinations of Methods}

Because of the different limitations associated with culture-based and molecular methods for detecting antibiotic resistance, it can be useful to apply these approaches together (Jindal et al., 2006; Heuer et al., 2011a; Zhou et al., 2009; Sato et al., 2014). It is also increasingly common to apply multiple molecular methods within a single study. For example, Looft et al. (2012) applied a combination of metagenomics, qPCR array, and phylogenetics in their study on the effect of antibiotics on the intestinal microbiome of swine. The metagenomic analysis revealed 20 ARGs that were more abundant in the manure of medicated pigs. The qPCR array 
method was applied across more samples and confirmed these results but was not as comprehensive in its coverage of ARGs. Examining phylogenetics in parallel revealed that E. coli were also enriched in antibiotic-treated pigs, but this approach could not confirm whether or not the $E$. coli actually carried the ARGs of interest.

\section{Prospectus for Future Application of Molecular Tools in Agricultural Ecosystems}

Overall, successful assessment of antibiotic resistance in agricultural ecosystems with molecular methods depends on focused research questions, selection of appropriate molecular targets and corresponding methods, combining with other methods if necessary, and inclusion of relevant controls to address the research questions. Limitations of existing molecular approaches include the inability to match ARGs with corresponding host bacteria, verify the viability of the hosts, or demonstrate the functionality of the ARG and/or its ability to be horizontally transferred. One key methodological frontier is the continued development of metagenomic techniques and associated data analysis methods, which could permit analysis of which bacteria are carrying which ARGs and whether they are associated with gene transfer elements. Another methodological frontier is the development of standard protocols and gene targets for monitoring antibiotic resistance in the environment, which would facilitate large-scale environmental monitoring efforts and cross-study comparisons. Because of the potential for horizontal gene transfer, it is critical that such efforts not be restricted to traditional fecal indicators or pathogens, with the European COST action monitoring scheme representing an early adopter of such an approach. A third methodological frontier emerges from the need to better understand the role of horizontal gene transfer in the dissemination of antibiotic resistance in agricultural ecosystems. Experimental assays and metagenomic approaches must be integrated to understand both the physicochemical and biological factors influencing gene transfer, including antibiotic use and metals, and the scope of gene transfer in the environment. Ultimately, antibiotic resistance is of concern due to its impact on human health. Presently human health risk models are typically formulated for specific pathogens based on dose-response data and corresponding concentrations via likely exposure routes (e.g., ingestion and inhalation) and have incorporated only limited spatial and temporal information on associated microbial communities (Port et al., 2012). Such models have limited applicability for assessing human health risks from antibiotic resistance and ideally should be revamped to consider ARGs and horizontal gene transfer processes (Ashbolt et al., 2013). Therefore, coordinated effort between the advancement of molecular tools for assessment of antibiotic risk and the development of appropriate risk assessment models is required.

\section{Acknowledgments}

This project was supported by Agriculture and Food Research Initiative Competitive Grant no. 2013-68003-21256 from the USDA National Institute of Food and Agriculture. Amy Pruden was also supported by USDA NIFA Grant no. 2014-05280.

\section{References}

Agerso, Y., and D. Sandvang. 2005. Class 1 integrons and tetracycline resistance genes in Alcaligenes, Arthrobacter, and Pseudomonas spp. isolated from pigsties and manured soil. Appl. Environ. Microbiol. 71:7941-7947. doi:10.1128/AEM.71.12.7941-7947.2005

Agerso, Y., G. Wulff, E. Vaclavik, B. Halling-Sorensen, and L.B. Jensen. 2006. Effect of tetracycline residues in pig manure slurry on tetracycline-resistant bacteria and resistance gene tet $(\mathrm{M})$ in soil microcosms. Environ. Int. 32:876-882. doi:10.1016/j.envint.2006.05.008

Allen, H.K., L.A. Moe, J. Rodbumrer, A. Gaarder, and J. Handelsman. 2009. Functional metagenomics reveals diverse beta-lactamases in a remote Alaskan soil. ISME J. 3:243-251. doi:10.1038/ismej.2008.86

Allen, H.K., J. Donato, H.H. Wang, K.A. Cloud-Hansen, J. Davies, and J. Handelsman. 2010. Call of the wild: Antibiotic resistance genes in natural environments. Nat. Rev. Microbiol. 8:251-259. doi:10.1038/nrmicro2312

Angenent, L.T., M. Mau, U. George, J.A. Zahn, and L. Raskin. 2008. Effect of the presence of the antimicrobial tylosin in swine waste on anaerobic treatment. Water Res. 42:2377-2384. doi:10.1016/j.watres.2008.01.005

Ashbolt, N.J., A. Amezquita, T. Backhaus, P. Borriello, K.K. Brandt, P. Collignon, A. Coors, R. Finley, W.H. Gaze, T. Heberer, J.R. Lawrence, D.G.J. Larrson, S.A. McEwen, J.J. Ryan, J. Schonfeld, P. Silley, J.R. Snape, C. Van den Eede, and E. Topp. 2013. Human health risk assessment (HHRA) for environmental development and transfer of antibiotic resistance. Environ. Health Perspect. 121:993-1001.

Balcazar, J.L. 2014. Bacteriophages as vehicles for antibiotic resistance genes in the environment. PLoS Pathog. 10:e1004219. doi:10.1371/journal. ppat.1004219

Bengtsson-Palme, J., F. Boulund, J. Fick, E. Kristiansson, and D.G.J. Larsson. 2014. Shotgun metagenomics reveals a wide array of antibiotic resistance genes and mobile elements in a polluted lake in India. Front. Microbiol. 5:1-14.

Berendonk, T.U., C.M. Manaia, C. Merlin, D. Fatta-Kassinos, E. Cytryn, F. Walsh, H. Buergmann, H. Sorum, M. Norstrom, M.N. Pons, et al. 2015. Tackling antibiotic resistance: The environmental framework. Nat. Rev. Microbiol. 13:310-317. doi:10.1038/nrmicro3439

Binh, C.T.T., H. Heuer, M. Kaupenjohann, and K. Smalla. 2008. Piggery manure used for soil fertilization is a reservoir for transferable antibiotic resistance plasmids. FEMS Microbiol. Ecol. 66:25-37. doi:10.1111/j.1574-6941.2008.00526.x

Brabban, A.D., E. Hite, and T.R. Callaway. 2005. Evolution of foodborne pathogens via temperate bacteriophage-mediated gene transfer. Foodborne Pathog. Dis. 2:287-303. doi:10.1089/fpd.2005.2.287

Canchaya, C., C. Proux, G. Fournous, A. Bruttin, and H. Brussow. 2003. Prophage genomics. Microbiol. Mol. Biol. Rev. 67:238-276. doi:10.1128/ MMBR.67.2.238-276.2003

Carattoli, A., A. Bertini, L. Villa, V. Falbo, K.L. Hopkins, and E.J. Threlfall. 2005. Identification of plasmids by PCR-based replicon typing. J. Microbiol. Methods 63:219-228. doi:10.1016/j.mimet.2005.03.018

Casjens, S. 2003. Prophages and bacterial genomics: What have we learned so far? Mol. Microbiol. 49:277-300. doi:10.1046/j.1365-2958.2003.03580.x

Chee-Sanford, J.C., R.I. Aminov, I.J. Krapac, N. Garrigues-Jeanjean, and R.I. Mackie. 2001. Occurrence and diversity of tetracycline resistance genes in lagoons and groundwater underlying two swine production facilities. Appl. Environ. Microbiol. 67:1494-1502. doi:10.1128/ AEM.67.4.1494-1502.2001

Chen, I., and D. Dubnau. 2004. DNA uptake during bacterial transformation. Nat. Rev. Microbiol. 2:241-249. doi:10.1038/nrmicro844

Cochetti, I., E. Tili, M. Vecchi, A. Manzin, M. Mingoia, P.E. Varaldo, and M.P. Montanari. 2007. New Tn916-related elements causing erm(B)-mediated erythromycin resistance in tetracycline-susceptible pneumococci. J. Antimicrob. Chemother. 60:127-131. doi:10.1093/jac/dkm120

Cochetti, I., E. Tili, M. Mingoia, P.E. Varaldo, and M.P. Montanari. 2008. $\operatorname{Erm}(B)$-carrying elements in tetracycline-resistant pneumococci and correspondence between Tn1545 and Tn6003. Antimicrob. Agents Chemother. 52:1285-1290. doi:10.1128/AAC.01457-07

Colomer-Lluch, M., L. Imamovic, J. Jofre, and M. Muniesa. 2011 a. Bacteriophages carrying antibiotic resistance genes in fecal waste from cattle, pigs, and poultry. Antimicrob. Agents Chemother. 55:4908-4911. doi:10.1128/ AAC.00535-11

Colomer-Lluch, M., J. Jofre, and M. Muniesa. 2011b. Antibiotic resistance genes in the bacteriophage DNA fraction of environmental samples. PLoS One 6:e17549. doi:10.1371/journal.pone.0017549

Coque, T.M., F. Baquero, and R. Cantón. 2008. Increasing prevalence of ESBLproducin Enterobacteriaceae in Europe. Euro Surveill. 13:5437-5453.

Couturier, M., F. Bex, P.L. Berquist, and W.K. Maas. 1988. Identification and classification of bacterial plasmids. Microbiol. Rev. 52:375-395. 
de Castro, A.P., G.D.R. Fernandes, and O.L. Franco. 2014. Insights into novel antimicrobial compounds and antibiotic resistance genes from soil metagenomes. Front. Microbiol. 5:1-9.

Del Grosso, M., R. Camilli, B. Libisch, M. Fuzi, and A. Pantosti. 2009. New composite genetic element of the $\operatorname{Tn} 916$ family with dual macrolide resistance genes in a Streptococcus pneumonia isolate belonging to clonal complex 271. Antimicrob. Agents Chemother. 53:1293-1294. doi:10.1128/ AAC.01066-08

Demaneche, S., E. Kay, F. Gourbiere, and P. Simonet. 2001. Natural transformation of Pseudomonas fuorescens and Agrobacterium tumefaciens in soil. Appl. Environ. Microbiol. 67:2617-2621. doi:10.1128/ AEM.67.6.2617-2621.2001

Dodd, M.C. 2012. Potential impacts of disinfection processes on elimination and deactivation of antibiotic resistance genes during water and wastewater treatment. J. Environ. Monit. 14:1754-1771. doi:10.1039/c2em00006g

Donato, J.J., L.A. Moe, B.J. Converse, K.D. Smart, F.C. Berklein, P.S. McManus, and J. Handelsman. 2010. Metagenomic analysis of apple orchard soil reveals antibiotic resistance genes encoding predicted bifunctional proteins. Appl. Environ. Microbiol. 76:4396-4401. doi:10.1128/ AEM.01763-09

Durso, L.M., D.N. Miller, and B. Wienhold. 2012. Distribution and quantification of antibiotic resistant genes and bacteria across agricultural and nonagricultural metagenomes. PLoS One 7:e48325. doi:10.1371/journal. pone. 0048325

Engemann, C.A., P.L. Keen, C.W. Knapp, K.J. Hall, and D.W. Graham. 2008. Fate of tetracycline resistance genes in aquatic systems: Migration from the water column to peripheral biofilms. Environ. Sci. Technol. 42:51315136. doi:10.1021/es800238e

Facinelli, B., M.C. Roberts, E. Giofanetti, C. Casolari, U. Fabio, and P.E. Varaldo. 1993. Genetic-basis of tetracycline resistance in food-borne isolates of Listeria innocua. Appl. Environ. Microbiol. 59:614-616.

Fang, H., H.F. Wang, L. Cai, and Y.L. Yu. 2015. Prevalence of antibiotic resistance genes and bacterial pathogens in long-term manured greenhouse soils as revealed by metagenomic survey. Environ. Sci. Technol. 49:10951104. doi: $10.1021 /$ es $504157 \mathrm{y}$

Fineran, P.C., N.K. Petty, and G.P.C. Salmond. 2009. Transduction: Host DNA transfer by bacteriophages. In: M. Schaechter, editor, The desk encyclopedia of microbiology. Elsevier Academic Press, San Diego, CA. p. 666-679.

Forsberg, K.J., S. Patel, M.K. Gibson, C.L. Lauber, R. Knight, N. Fierer, and G. Dantas. 2014. Bacterial phylogeny structures soil resistomes across habitats. Nature 509:612-615. doi:10.1038/nature 13377

Forsberg, K.J., A. Reyes, B. Wang, E.M. Selleck, and M.O. Sommer. 2012. The shared antibiotic resistome of soil bacteria and human pathogens. Science 337:1107-1111. doi:10.1126/science. 1220761

Frost, L.S., R. Leplae, A.O. Summers, and A. Toussaint. 2005. Mobile genetic elements: The agents of open source evolution. Nat. Rev. Microbiol. 3:722732. doi: $10.1038 /$ nrmicro 1235

Garder, J.L., T.B. Moorman, and M.L. Soupir. 2014. Transport and persistence of tylosin-resistant enterococci, erm genes, and tylosin in soil and drainage water from fields receiving swine manure. J. Environ. Qual. 43:1484-1493. doi:10.2134/jeq2013.09.0379

Gibson, M.K., K.J. Forsberg, and G. Dantas. 2015. Improved annotation of antibiotic resistance determinants reveals microbial resistomes cluster by ecology. ISME J. 9:207-216. doi:10.1038/ismej.2014.106

Gillespie, D.E., S.F. Brady, A.D. Bettermann, N.P. Cianciotto, M.R. Liles, and M.R. Rondon. 2002. Isolation of antibiotics turbomycin A and B from a metagenomic library of soil microbial DNA. Appl. Environ. Microbiol. 68:4301-4306. doi:10.1128/AEM.68.9.4301-4306.2002

Goessweiner-Mohr, N., K. Arends, W. Keller, and E. Grohmannc. 2013. Conjugative type IV secretion systems in Gram-positive bacteria. Plasmid 70:289-302. doi:10.1016/j.plasmid.2013.09.005

Gotz, A., R. Pukail, E. Smit, E. Tietze, R. Prager, H. Tschape, J.D. Van Elsas, and K. Smalla. 1996. Detection and characterization of broad-host-range plasmids in environmental bacteria by PCR. Appl. Environ. Microbiol. 62:2621-2628.

Goyer, C., and C.E. Dandie. 2012. Quantification of microorganisms targeting conserved genes in complex environmental samples using quantitative polymerase chain reaction. In: M. Filion, editor, Quantitative real-time PCR in applied microbiology. Horizon Press, Portland, OR. p. 87-106.

Guo, F., and T. Zhang. 2013. Biases during DNA extraction of activated sludge samples revealed by high throughput sequences. Appl. Microbiol. Biotechnol. 97:4607-4616.

Henry, C.S., R. Overbeek, F.F. Xia, A.A. Best, E. Glass, J. Gilbert, P. Larsen, R. Edwards, T. Disz, F. Meyer, et al. 2011. Connecting genotype to phenotype in the era of high-throughput sequencing. Biochim. Biophys. Acta. 1810(10):967-977.
Heuer, H., and K. Smalla. 2007. Manure and sulfadiazine synergistically increased bacterial antibiotic resistance in soil over at least two months. Environ. Microbiol. 9:657-666. doi:10.1111/j.1462-2920.2006.01185.x

Heuer, H., H. Schmitt, and K. Smalla. 2011a. Antibiotic resistance gene spread due to manure application on agricultural fields. Curr. Opin. Microbiol. 14:236-243. doi:10.1016/j.mib.2011.04.009

Heuer, H., Q. Solehati, U. Zimmerling, K. Kleineidam, M. Schloter, T. Muller, A. Focks, S. Thiele-Bruhn, and K. Smalla. 2011b. Accumulation of sulfonamide resistance genes in arable soils due to repeated application of manure containing sulfadiazine. Appl. Environ. Microbiol. 77:2527-2530. doi:10.1128/AEM.02577-10

Hoorfar, J., B. Malorney, A. Abdulmawjood, N. Cook, M. Wagner, and P. Fach. 2004. Practical considerations in design of internal amplification controls for diagnostic PCR assays. J. Clin. Microbiol. 42:1863-1868. doi:10.1128/JCM.42.5.1863-1868.2004

Jindal, A., S. Kocherginskaya, A. Mehboob, M. Robert, R.I. Mackie, L. Raskin, and J.L. Zilles. 2006. Antimicrobial use and resistance in swine waste treatment systems. Appl. Environ. Microbiol. 72:7813-7820. doi:10.1128/ AEM.01087-06

Johnston, C., B. Martin, G. Fichant, P. Polard, and J.P. Claverys. 2014. Bacterial transformation: Distribution, shared mechanisms and divergent control. Nat. Rev. Microbiol. 12:181-196. doi:10.1038/nrmicro3199

Klümper, U., I. Riber, A. Dechesne, A. Sannazzarro, L.H. Hansen, S.J. Sorensen, and B.F. Smets. 2015. Broad host range plasmids can invade an unexpectedly diverse fraction of a soil bacterial community. ISME J. 9:934-945. doi:10.1038/ismej.2014.191

Knapp, C.W., J. Dolfing, P.A.I. Ehlert, and D.W. Graham. 2010. Evidence of increasing antibiotic resistance gene abundances in archived soils since 1940. Environ. Sci. Technol. 44:580-587. doi:10.1021/es901221x

Koike, S., I.G. Krapac, H.D. Oliver, A.C. Yannarell, J.C. Chee-Sanford, R.I. Aminov, and R.I. Mackie. 2007. Monitoring and source tracking of tetracycline resistance genes in lagoons and groundwater adjacent to swine production facilities over a 3-year period. Appl. Environ. Microbiol. 73:4813-4823. doi:10.1128/AEM.00665-07

Kristiansson, E., J. Fick, A. Janzon, R. Grabic, C. Rutgersson, B. Weijdegard, H. Soderstrom, and D.G.J. Larsson. 2011. Pyrosequencing of antibiotic-contaminated river sediments reveals high levels of resistance and gene transfer elements. PLoS One 6:e17038. doi:10.1371/journal.pone.0017038

Lang, K.S., J.M. Anderson, S. Schwarz, L. Williamson, J. Handelsman, and R.S. Singer. 2010. Novel florfenicol and chloramphenicol resistance gene discovered in Alaskan soil by using functional metagenomics. Appl. Environ. Microbiol. 76:5321-5326. doi:10.1128/AEM.00323-10

Lennon, J.T. 2011. Replication, lies and lesser-known truths regarding experimental design in environmental microbiology. Environ. Microbiol. 13:1383-1386. doi:10.1111/j.1462-2920.2011.02445.x

Levy-Booth, D.J., R.G. Campbell, R.H. Gulden, M.M. Hart, J.R. Powell, J.N. Klironomos, K.P. Pauls, C.J. Swanton, J.T. Trevors, and K.E. Dunfield. 2007. Cycling of extracellular DNA in the soil environment. Soil Biol. Biochem. 39:2977-2991. doi:10.1016/j.soilbio.2007.06.020

Li, L., N. Mendis, H. Triqui, J.D. Oliver, and S.P. Faucher. 2014. The importance of the viable but non-culturable state in human bacterial pathogens. Front. Microbiol. 5:1-20.

Liao, Y.T., S.C. Kuo, Y.T. Lee, C.P. Chen, S.W. Lin, L.J. Shen, C.P. Fung, W.L. Cho, and T.L. Chen. 2014. Sheltering effect and indirect pathogenesis of carbapenem-resistant Acinetobacter baumannii in polymicrobial infection. Antimicrob. Agents Chemother. 58:3983-3990. doi:10.1128/ AAC.02636-13

Lim, H.K., E.J. Chung, J.C. Kim, G.J. Choi, K.S. Jang, and Y.R. Chung. 2005. Characterization of a forest soil metagenome clone that confers indirubin and indigo production on Escherichia coli. Appl. Environ. Microbiol. 71:7768-7777. doi:10.1128/AEM.71.12.7768-7777.2005

Looft, T., T.A. Johnson, H.K. Allen, D.O. Bayles, D.P. Alt, R.D. Stedtfeld, W.J. Sul, T.M. Stedtfeld, B. Chai, J.R. Cole, S.A. Hashsham, J.M. Tiedje, and T.B. Stanton. 2012. In-feed antibiotic effects on the swine intestinal microbiome. Proc. Natl. Acad. Sci. USA 109:1691-1696. doi:10.1073/ pnas. 1120238109

Lorenz, M.G., and W. Wackernagel. 1994. Bacterial gene transfer by natural genetic transformation in the environment. Microbiol. Rev. 58:563-602.

Lu, N., J.L. Zilles, and T.H. Nguyen. 2010. Adsorption of extracellular chromosomal DNA and its effects on natural transformation of Azotobacter vinelandii. Appl. Environ. Microbiol. 76:4179-4184. doi:10.1128/ AEM.00193-10

Luo, G., and I. Angelidaki. 2014. Analysis of bacterial communities and bacterial pathogens in a biogas plant by the combination of ethidium monoazide, PCR and Ion Torrent sequencing. Water Res. 60:156-163. doi:10.1016/j. watres.2014.04.047 
MacNeil, I.A., C.L. Tiong, C. Minor, P.R. Augus, T.H. Grossman, and K.A. Loiacono. 2001. Expression and isolation of antimicrobial small molecules from soil DNA libraries. J. Mol. Microbiol. Biotechnol. 3:301-308.

Maier, T., M. Güell, and L. Serrano. 2009. Correlation of mRNA and protein in complex biological samples. FEBS Lett. 583:3966-3973. doi:10.1016/j. febslet.2009.10.036

Malik, A., E.K. Celik, C. Bohn, U. Bockelmann, K. Knobel, and E. Grohmann. 2008. Detection of conjugative plasmids and antibiotic resistance genes in anthropogenic soils from Germany and India. FEMS Microbiol. Lett. 279:207-216. doi:10.1111/j.1574-6968.2007.01030.x

Markowitz, V.M., I.M.A. Chen, K. Palaniappan, K. Chu, and E. Szeto. 2012. IMG: The integrated microbial genomes database and comparative analysis system. Nucleic Acids Res. 40:D115-D122. doi:10.1093/nar/ gkr1044

Marti, R., A. Scott, Y.C. Tien, R. Murray, L. Sabourin, Y. Zhang, and E. Topp. 2013. Impact of manure fertilization on the abundance of antibiotic-resistant bacteria and frequency of detection of antibiotic resistance genes in soil and on vegetables at harvest. Appl. Environ. Microbiol. 79:57015709. doi:10.1128/AEM.01682-13

McArthur, A.G., N. Waglechner, F. Nizam, A. Yan, M.A. Azad, A.J. Baylay, K. Bhullar, M.J. Canova, G. De Pascale, L. Ejim, L. Kalan, A.M. King, K. Koteva, M. Morar, M.R. Mulvey, J.S. O’Brien, A.C. Pawlowski, L.J. Piddock, P. Spanogiannopoulos, A.D. Sutherland, I. Tang, P.L. Taylor, M. Thaker, W. Wang, M. Yan, T. Yu, and G.D. Wright. 2013. The comprehensive antibiotic resistance database. Antimicrob. Agents Chemother. 57:3348-3357. doi:10.1128/AAC.00419-13

McGarvey, K.M., K. Queitsch, and S. Fields. 2012. Wide variation in antibiotic resistance proteins identified by functional metagenomic screening of a soil DNA library. Appl. Environ. Microbiol. 78:1708-1714. doi:10.1128/ AEM.06759-11

McKinney, C.W., K.A. Loftin, M.T. Meyer, J.G. Davis, and A. Pruden. 2010. Tet and sul antibiotic resistance genes in livestock lagoons of various operation type, configuration, and antibiotic occurrence. Environ. Sci. Technol. 44:6102-6109. doi:10.1021/es9038165

McKinney, C.W., and A. Pruden. 2012. Ultraviolet disinfection of antibiotic resistant bacteria and their antibiotic resistance genes in water and wastewater. Environ. Sci. Technol. 46(24):13393-13400. doi:1 0.1021/ es $303652 q$

Meyer, F., D. Paarmann, M. D'Souza, R. Olson, E.M. Glass, M. Kubal, T. Paczian, A. Rodriguez, R. Stevens, A. Wilke, J. Wilkening, and R.A. Edwards. 2008. The metagenomics RAST server: A public resource for the automatic phylogenetic and functional analysis of metagenomes. BMC Bioinf. 9:386. doi:10.1186/1471-2105-9-386

Mezger, A., E. Gullberg, J. Göransson, A. Zorzet, D. Herthnek, E. Tano, M. Nilsson, and D.I. Andersson. 2015. A general method to rapidly determine antibiotic susceptibility and species in bacterial infections. J. Clin. Microbiol. 53:425-432. doi:10.1128/JCM.02434-14

Musovic, S., A. Dechesne, J. Sorensen, and B.F. Smets. 2010. Novel assay to assess permissiveness of a soil microbial community toward receipt of mobile genetic elements. Appl. Environ. Microbiol. 76:4813-4818. doi:10.1128/ AEM.02713-09

Musovic, S., U. Klümper, A. Dechesne, J. Magid, and B.F. Smets. 2014. Long-term manure exposure increases soil bacterial community potential for plasmid uptake. Environ. Microbiol. Rep. 6:125-130 doi: $10.1111 / 1758-2229.12138$

Nandi, S., J.J. Maurer, C. Hofacre, and A.O. Summers. 2004. Gram-positive bacteria are a major reservoir of Class 1 antibiotic resistance integrons in poultry litter. Proc. Natl. Acad. Sci. USA 101:7118-7122. doi:10.1073/ pnas.0306466101

Nesme, J., S. Cécillon, T.O. Delmont, J.M. Monier, T.M. Vogel, and P. Simonet. 2014. Large-scale metagenomic-based study of antibiotic resistance in the environment. Curr. Biol. 24:1096-1100. doi:10.1016/j.cub.2014.03.036

Nesme, J., and P. Simonet. 2015. The soil resistome: A critical review on antibiotic resistance origins, ecology and dissemination potential in telluric bacteria. Environ. Microbiol. 17:913-930. doi:10.1111/1462-2920.12631

Nielsen, K.M., M.D.M. Van Weerelt, T.N. Berg, A.M. Bones, A.N. Hagler, and J.D. Van Elsas. 1997. Natural transformation and availability of transforming DNA to Acinetobacter calcoaceticus in soil microcosms. Appl. Environ. Microbiol. 63:1945-1952.

Nocker, A., C.Y. Cheung, and A.K. Camper. 2006. Comparison of propidium monoazide with ethidium monoazide for differentiation of live vs. dead bacteria by selective removal of DNA from dead cells. J. Microbiol. Methods 67:310-320. doi:10.1016/j.mimet.2006.04.015

Ochman, H., J.G. Lawrence, and E.A. Groisman. 2000. Lateral gene transfer and the nature of bacterial innovation. Nature 405:299-304. doi: $10.1038 / 35012500$
Peak, N., C.W.Knapp, R.K. Yang, M.M. Hanfelt, M.S. Smith, D.S. Aga, and D.W. Graham. 2007. Abundance of six tetracycline resistance genes in wastewater lagoons at cattle feedlots with different antibiotic use strategies. Environ. Microbiol. 9:143-151. doi:10.1111/j.1462-2920.2006.01123.x

Pehrsson, E.C., K.J. Forsberg, M.K. Gibson, S. Ahmadi, and G. Dantas. 2013. Novel resistance functions uncovered using functional metagenomic investigations of resistance reservoirs. Front. Microbiol. 4:145.

Pei, R., S.C. Kim, K.H. Carlson, and A. Pruden. 2006. Effect of river landscape on the sediment concentrations of antibiotics and corresponding antibiotic resistance genes (ARG). Water Res. 40:2427-2435. doi:10.1016/j. watres.2006.04.017

Pei, R., J.M. Cha,, K.H. Carlson, and A. Pruden. 2007. Biological treatment of antibiotic resistance genes (ARG) in dairy lagoon water. Environ. Sci. Technol. 41(14):50018-5013. doi:10.1016/j.watres.2006.04.017

Perry, J.A., and G.D. Wright. 2013. The antibiotic resistance "mobilone": Searching for the link between environment and clinic. Front. Microbiol. 4:138. doi: $10.3389 /$ fmicb. 2013.00138

Pietramellara, G., J. Ascher, F. Borgogni, M.T. Ceccherini, G. Guerri, and P. Nannipieri. 2009. Extracellular DNA in soil and sediment: Fate and ecological relevance. Biol. Fertil. Soils 45:219-235. doi:10.1007/ s00374-008-0345-8

Popowska, M., M. Rzeczycka, A. Miernik, A. Krawczyk-Balska, F. Walsh, and B. Duffy. 2011. Influence of soil use on prevalence of tetracycline, streptomycin, and erythromycin resistance and associated resistance genes. Antimicrob. Agents Chemother. 350:180-189.

Port, J.A., J.C. Wallace, W.C. Griffith, and E.M. Faustman. 2012. Metagenomic profiling of microbial composition and antibiotic resistance determinants in Puget Sound. PLoS One 7:E48000. doi:10.1371/journal.pone.0048000

Prosser, J.I. 2010. Replicate or lie. Environ. Microbiol. 12:1806-1810. doi:10.1111/j.1462-2920.2010.02201.x

Pruden, A., R. Pei, H. Storteboom, and K.H. Carlson. 2006. Antibiotic resistance genes as emerging contaminants: Studies in northern Colorado. Environ. Sci. Technol. 40:7445-7450. doi:10.1021/es0604131

Pruden, A., M. Arabi, and H.N. Storteboom. 2012. Correlation between upstream human activities and riverine antibiotic resistance genes. Environ. Sci. Technol. 46:11541-11549. doi:10.1021/es302657r

Ray, J.L., and K.M. Nielsen. 2005. Experimental methods for assaying natural transformation and inferring horizontal gene transfer. Methods Enzymol. 395:491-520. doi:10.1016/S0076-6879(05)95026-X

Renaud, C.S., J.J. Pasternak, and B.R. Glick. 1989. Integration of exogenous DNA into the genome of Azotobacter vinelandii. Arch. Microbiol. 152:437-440. doi:10.1007/BF00446925

Roberts, A.P., I.J. Davis, L. Seville, A. Villedieu, and P. Mullany. 2006. Characterization of the ends and target site of a novel tetracycline resistance encoding conjugative transposon from Enterococcus faecium 664.1 H1. J. Bacteriol. 188:4356-4361. doi:10.1128/JB.00129-06

Roberts, A.P., and P. Mullany. 2011. Tn916-like genetic elements: A diverse group of modular mobile elements conferring antibiotic resistance. FEMS Microbiol. Rev. 35:856-871. doi:10.1111/j.1574-6976.2011.00283.x

Roberts, M.C. 2012. Acquired tetracycline resistance genes. In: T.J. Dougherty and M.J. Pucci, editors, Antibiotic discovery and development. Vol. 1 and 2. Springer, New York. p. 543-568.

Rodríguez, R.A., S. Bounty, and K.G. Linden. 2013. Long-range quantitative PCR for determining inactivation of adenovirus 2 by ultraviolet light. J. Appl. Microbiol. 114:1854-1865. doi:10.1111/jam.12169

Rothrock, M.J., Jr., P.L. Keen, K.L. Cook, L.M. Durso, A.M. Franklin, and R.S. Dungan. 2016. How should we be determining background and baseline antibiotic resistance levels in agroecosystem research? J. Environ. Qual. doi:10.2134/jeq2015.06.0327 (in press).

Rudi, K., B. Moen, S.M. Dromtorp, and A.L. Holck. 2005. Use of ethidium monoazide and PCR in combination for quantification of viable and dead cells in complex samples. Appl. Environ. Microbiol. 71:1018-1024. doi:10.1128/AEM.71.2.1018-1024.2005

Sato, T., T. Okubo, M. Usui, S. Yokota, S. Izumiyama, and Y. Tamura. 2014. Association of veterinary third-generation cephalosporin use with the risk of emergence of extended-spectrum-cephalosporin resistance in Escherichia coli from dairy cattle in Japan. PLoS One 9:e96101. doi:10.1371/journal. pone.0096101

Schlüter, A., R. Szczepanowski, A. Pühler, and E.M. Top. 2007. Genomics of IncP-1 antibiotic resistance plasmids isolated from wastewater treatment plants provides evidence for a widely accessible drug resistance gene pool. FEMS Microbiol. Rev. 31:449-477. doi:10.1111/j.1574-6976.2007.00074.x

Schmieder, R., and R. Edwards. 2012. Insights into antibiotic resistance through metagenomics approaches. Future Microbiol. 7:73-89. doi:10.2217/ fmb.11.135 
Schmieger, H., and P. Schicklmaier. 1999. Transduction of multiple drug resistance of Salmonella enterica serovar typhimurium DT104. FEMS Microbiol. Lett. 170:251-256. doi:10.1111/j.1574-6968.1999.tb13381.x

Seitz, P., and M. Blokesch. 2013. Cues and regulatory pathways involved in natural competence and transformation in pathogenic and environmental Gram-negative bacteria. FEMS Microbiol. Rev. 37:336-363. doi:10.1111/j.1574-6976.2012.00353.x

Smalla, K., and P.A. Sobecky. 2002. The prevalence and diversity of mobile genetic elements in bacterial communities of different environmental habitats: Insights gained from different methodological approaches. FEMS Microbiol. Ecol. 42:165-175. doi:10.1111/j.1574-6941.2002.tb01006.x

Smith, M.S., R.K. Yang, C.W. Knapp, Y. Niu, N. Peak, M.M. Hanfelt, J.C. Galland, and D.W. Graham. 2004. Quantification of tetracycline resistance genes in feedlot lagoons by real-time PCR. Appl. Environ. Microbiol. 70:7372-7377. doi:10.1128/AEM.70.12.7372-7377.2004

Stewart, P.S., and J.W. Costerton. 2001. Antibiotic resistance of bacteria in biofilms. J. Lancet 358:135-138. doi:10.1016/S0140-6736(01)05321-1

Storteboom, H., M. Arabi, J.G. Davis, B. Crimi, and A. Pruden. 2010. Identification of antibiotic-resistance-gene molecular signatures suitable as tracers of pristine river, urban, and agricultural sources. Environ. Sci. Technol. 44:1947-1953. doi: 10.1021/es902893f

Su, J.Q., B. Wei, C.Y. Xu, M. Qiao, and Y.G. Zhu. 2014. Functional metagenomic characterization of antibiotic resistance genes in agricultural soils from China. Environ. Int. 65:9-15. doi:10.1016/j.envint.2013.12.010

Suess, J., S. Volz, U. Obst, and T. Schwartz. 2009. Application of a molecular biology concept for the detection of DNA damage and repair during UV disinfection. Water Res. 43:3705-3716. doi:10.1016/j.watres.2009.05.048

Thames, C.H., A. Pruden, R.E. James, P.P. Ray, and K.F. Knowlton. 2012. Excretion of antibiotic resistance genes by dairy calves fed milk replacers with varying doses of antibiotics. Front. Microbiol. 10:139.

The White House. 2015. National action plan for combatting antibiotic resistant bacteria. www.whitehouse.gov/sites/default/files/docs/national_action_plan_for_combating_antibotic-resistant_bacteria.pdf (accessed 9 Dec. 2015).

Thomas, T., J. Gilbert, and M. Folker. 2012. Metagenomics: A guide from sampling to data analysis. Microb. Inform. Exp. 2:3. doi:10.1186/2042-5783-2-3

Trebesius, K.H., K. Panthel, S. Strobel, K. Vogt, G. Faller, T. Kirchner, M. Kist, J. Heesemann, and R. Haas. 2000. Rapid and specific detection of Helicobacter pylori macrolide resistance in gastric tissue by fluorescent in situ hybridisation. Gut 46:608-614. doi:10.1136/gut.46.5.608

Tsubakishita, S., K. Kuwahara-Arai, T. Sasaki, and K. Hiramatsu. 2010. Origin and molecular evolution of the determinant of methicillin resistance in staphylococci. Antimicrob. Agents Chemother. 54:4352-4359. doi:10.1128/AAC.00356-10

Uchiyama, T., and K. Miyazaki. 2009. Functional metagenomics for enzyme discovery: Challenges to efficient screening. Curr. Opin. Biotechnol. 20:616622. doi:10.1016/j.copbio.2009.09.010
Udikovic-Kolic, N., F. Wichmann, N.A. Broderick, and J. Handelsman. 2014. Bloom of resident antibiotic-resistant bacteria in soil following manure fertilization. Proc. Natl. Acad. Sci. USA 111:15202-15207. doi:10.1073/ pnas. 1409836111

Wagner, M., H. Smidt, A. Loy, and J. Zhou. 2007. Unravelling microbial communities with DNA-microarrays: Challenges and future directions. Microb. Ecol. 53:498-506. doi:10.1007/s00248-006-9197-7

Wang, F.H., M. Qiao, J.Q. Su, Z. Chen, X. Zhou, and Y.G. Zhu. 2014. High throughput profiling of antibiotic resistance genes in urban park soils with reclaimed water irrigation. Environ. Sci. Technol. 48:9079-9085. doi:10.1021/es502615e

Wichmann, F., N. Udikovic-Kolic, S. Andrew, and J. Handelsman. 2014. Diverse antibiotic resistance genes in dairy cow manure. MBio 5:e01017-e13.

Wilson, I.G. 1997. Inhibition and facilitation of nucleic acid amplification. Appl. Environ. Microbiol. 63:3741-3751.

Witte, W. 2004. International dissemination of antibiotic resistant strains of bacterial pathogens. Infect. Genet. Evol. 4:187-191. doi:10.1016/j. meegid.2003.12.005

Yang, Y., X.T. Jiang, and T. Zhang. 2014. Evaluation of a hybrid approach using UBLAST and BLASTX for metagenomic sequences annotation of specific functional genes. PLoS One 9:e110947. doi:10.1371/journal. pone. 0110947

Zechner, E.L., F. de la Cruz, R. Eisenbrandt, A.M. Grahn, G. Koraimann, E. Lanka, G. Muth, W. Pansegrau, C.M. Thomas, B.M. Wilkens, and M. Ztayka. 2003. Conjugative-DNA transfer processes. In: C.M. Thomas, editor, Horizontal gene pool: Bacterial plasmids and gene spread. CRC Press, Boca Raton, FL. p. 93-174.

Zhang, Y., D.D. Snow, D. Parker, Z. Zhou, and X. Li. 2013. Intracellular and extracellular antimicrobial resistance genes in the sludge of livestock waste management structures. Environ. Sci. Technol. 47:10206-10213.

Zhou, Z., L. Raskin, and J.L. Zilles. 2009. Identification of macrolide resistant microorganisms on antimicrobial-free swine farms. Appl. Environ. Microbiol. 75:5814-5820. doi:10.1128/AEM.00977-09

Zhou, W., L. Raskin, and J.L. Zilles. 2010. Effects of swine manure on macrolide, licosamide, and streptogramin B antimicrobial resistance in soils. Appl. Environ. Microbiol. 78:3028-3032. doi:10.1128/AEM.06920-11

Zhou, W., Y. Wang, and J. Lin. 2012. Functional cloning and characterization of antibiotic resistance genes from the chicken gut microbiome. Appl. Environ. Microbiol. 78:3028-3032. doi:10.1128/AEM.06920-11

Zhu, Y.G., T.A. Johnson, T.Q. Su, M. Qiao, G.X. Guo, R.D. Stedtfeld, S.A. Hashsham, and J.M. Tiedje. 2013. Diverse and abundant antibiotic resistance genes in Chinese swine farms. Proc. Natl. Acad. Sci. USA 110:34353440. doi: $10.1073 /$ pnas. 1222743110 